\title{
The Enforcement of Mandatory Disclosure Rules*
}

\author{
Matthias Dahm† Paula González ${ }^{\ddagger}$ and Nicolás Porteiro ${ }^{\S}$
}

August 29, 2018

\begin{abstract}
This paper examines the incentives of a firm to invest in information about the quality of its product and to disclose its findings. If the firm conceals information, it might be detected and fined. We show that optimal monitoring is determined by a trade-off. Overall, stricter enforcement reduces the incentives for selective reporting but crowds out information search. Our model implies that there are situations in which the relationship between the two monitoring instruments might be complementary. We also show that the welfare effects of mandatory disclosure depend on how it is enforced and that imperfect enforcement (in which some information remains concealed) might be optimal. In particular, the optimal fine might be smaller than the largest possible fine, even though the latter requires lower resource costs for inspections.
\end{abstract}

Keywords: strategic information transmission, scepticism, confidence effect, monitoring, penalty, fine, sanction, detection probability JEL Classification No.: D82, L15

${ }^{*}$ We would like to dedicate this paper to our co-author Nicolás Porteiro who passed away in April 2012. We are truly grateful for his friendship over many years and for all that we learned from him during that time. We are indebted to Inés Macho-Stadler, David Pérez-Castrillo and Daniel Seidmann for their careful reading of this paper. We are also grateful for valuable comments and suggestions from Helmut Bester, Farasat Bokhari, Subhasish M. Chowdhury, Thomas Gall, Paul Heidhues, Roberto Hernán-González, Navin Kartik, Sang-Hyun Kim, David Myatt, Pau Olivella, Carmelo Rodríguez-Álvarez, Marta Ronchetti, Roland Strausz, Marcos Vera-Hernández and Ansgar Wohlschlegel. Financial support from Fundación Ramón Areces is gratefully acknowledged. This work is partially supported by the research projects ECO2012-36480 and ECO2015-65408-R (Ministerio de Ciencia y Tecnología) and FEDER. All errors are our sole responsibility.

${ }^{\dagger}$ Corresponding author: University of Nottingham, School of Economics, University Park, Nottingham, NG7 2RD (UK); ORCID: orcid.org/0000-0002-3146-6802; email: Matthias.Dahm@nottingham.ac.uk.

‡Universidad Pablo de Olavide, Department of Economics; email: pgonzalez@upo.es.

$\S$ Universidad Pablo de Olavide, Department of Economics. 


\section{Introduction}

The US FDA Amendment Act 2007 requires that results must be posted on clinicaltrials.gov within a year of the completion of the trial for all trials with at least one site in the US. The FDA has the power to fine trial sponsors who do not comply but rarely does this ... The proposed EU Clinical Trials Regulation will require that summary results for every registered trial must be posted within one year of the completion of the trial, and the European Commission is discussing how to enforce this properly. Trial approval bodies in each country should consider expanding their monitoring of reporting, and ensure there is routine and open public audit of compliance for each individual trial.

\section{- The AllTrials Campaign $\square^{1}$}

In September 2004, the pharmaceutical company Merck voluntarily withdrew Vioxxa pain medication for arthritis-from the world market, because a clinical trial indicated that it increased the risk of heart attacks and strokes when taken for at least 18 months. Later, however, it was discovered that the company had failed to warn of the drug's dangers before the withdrawal. Following several scandals of so-called selective reporting of clinical trial results, the Food and Drug Administration Amendments Act (FDAAA) included the requirement of basic result reporting. Mandatory disclosure rules have also been established in other areas. For instance, manufacturers of SUVs are required to report rollover risk in the US. This regulation followed an inquiry into a series of deadly accidents during which it was found that the tire manufacturer Bridgestone/Firestone and the auto company Ford had failed to inform the public about the risk of Ford Explorer SUVs rolling over after tires blew out without warning $\mathrm{I}^{2}$

The above quote argues that mandatory disclosure rules for clinical trials should be complemented by strict enforcement. Considering monitoring through penalties and appropriate resources to conduct inspections, our research question is to identify the effects of such an enforcement $3^{3}$ Our results uncover a trade-off that optimal enforcement must balance and that policy discussions seem to be unaware of.

\footnotetext{
${ }^{1}$ The AllTrials campaign was launched in 2013 and at the time of writing has been signed by 93403 people and 740 organisations, see www.alltrials.net, accessed on 08/06/2018.

${ }^{2}$ On Vioxx see Berenson (2006), Antman et al. (2007) or Krumholz et al. (2007). On the FDAAA of September 2007 see Wood (2009). A detailed account of the SUV rollover scandal and the development of the Transportation Recall Enhancement, Accountability, and Documentation Act (TREAD) of November 2000 can be found in Fung et al. (2007). This book also discusses 17 other policy areas in which mandatory disclosure rules exist, including corporate financial disclosure, nutritional labeling and restaurant hygiene disclosure. Dranove and Jin (2010) offer further background on disclosure including a brief history.

${ }^{3}$ Fung et al. (2007) discuss (on p. 45-46) in detail the need for appropriate enforcement through monitoring and levying penalties. The FDAAA allows for civil penalties of as much as $\$ 10000$ per day but this is considered to be insufficient, see Prayle et al. (2012), Anderson et al. (2015) or Gopal (2015).
} 
We consider an information transmission game with hard evidence between a firm and the public (Milgrom, 1981; Grossman, 1981; Milgrom and Roberts, 1986; Seidmann and Winter, 1997). Hence it is not possible to fabricate the entire evidence of a clinical trial. The firm's product is either effective or has side-effects. A clinical trial potentially reveals these consequences to the firm. We allow for the possibility that the firm is not informed, so that the classical unravelling argument is mitigated (Dye, 1985; Shin, 1994). Consequently, a clinical trial can either be positive, negative or inconclusive (De Angelis et al., 2004). As with Shin's sanitization strategy, negative trials are suppressed and positive ones revealed, so that selective reporting is obtained in equilibrium.

The firm is required to disclose quality and safety problems. A monitoring agency invests resources in inspections and imposes a fine on the firm when it discovers that the firm conceals information. Enforcement is hence captured by a combination of a probability of detection and a fine $4^{4}$ Inspired by the Food and Drug Administration (FDA) that controls production plants and searches for contamination problems of which the seller might or might not be aware, the agency detects with some probability the existence of quality and safety problems. If this is the case, it also learns if information was concealed. An extension considers the case in which the agency does not search for information on the state of the world but detects selective reporting directly.

Selective reporting is considered to be harmful to society $5^{5}$ It might therefore appear that we can gain insights into optimal enforcement by drawing an analogy to law enforcement. Following Becker (1968) the deterrence of a harmful act depends on the expected fine. Moreover, it is optimal to combine a low probability of detection with the highest possible fine, for, if the fine were not as high as possible, then one could simultaneously increase the fine and decrease the probability of detection, thereby reducing enforcement costs. In this paper, however, we show that optimal enforcement in our context and in law enforcement differ in important ways. In particular, the largest possible fine might not be optimal, even though it requires fewer resources for inspections.

One difference between the two settings is that the firm's profits from concealing information depend on the monitoring policy. This is so, because the firm's profits depend on the beliefs of the public about the quality of its product. When no hard evidence is

As a result, there are calls for greater transparency in clinical trials, including Goldacre (2013), Chan et al. (2014), Hudson and Collins (2015), and the aforementioned AllTrials on-line petition.

${ }^{4}$ The agency can also be thought of as a surrogate for indirect enforcement like litigation, whistleblowing, political activism or journalistic investigations. Under this interpretation, different institutional designs of liability trials, confidentiality agreements, and legal protection for whistle-blowers might be related to different magnitudes of the probability of detection.

${ }^{5}$ For the case of clinical trials De Angelis et al. (2004, p. 477) write "The case against selective reporting is particularly compelling for research that tests interventions that could enter mainstream clinical practice. ... When research sponsors or investigators conceal the presence of selected trials, these studies cannot influence the thinking of patients, clinicians, other researchers, and experts who write practice guidelines or decide on insurance-coverage policy." 
revealed these beliefs depend on the interplay of two effects. On one hand, the failure of the firm to disclose positive information makes the public more pessimistic, as it is aware that information might be withheld. We refer to this as the scepticism effect of a lack of evidence ${ }^{6}$ On the other hand, if monitoring does not find concealed information, then the public becomes more optimistic; and the higher the probability of detection, the more optimistic the public becomes. We call this the confidence effect of monitoring.

Another difference between the two settings is that the firm has two alternatives to concealing evidence. The intended effect is to induce the firm to reveal its evidence honestly. But monitoring can also have the unintended effect of stopping the firm to acquire information in the first place. We denominate the latter as the disincentive effect of monitoring on information search and show that it might deter both honestly and selectively reported information. The incentive to invest in the former declines, as the confidence effect raises the opportunity costs of information. The incentive to invest in the latter declines, because stricter enforcement increases the expected fine.

It is well known that when enforcement is exogenous, a change from voluntary to mandatory disclosure reduces the incentives to invest in information.7 It is also well known that the strenght of this disincentive effect depends on the shape of the firm's profit function 8 In our model the precise condition for the disincentive effect not to crowd out investment in information completely is a generalization of convexity of the profit function that allows for both convex and concave segments. We assume that the firm's profit function is a general function of the public's beliefs but provide a microfoundation for a convex relationship when treatment effects are more likely to be moderate than strong.9

Our first contribution is to deepen our understanding of the disincentive effect. Optimal monitoring is determined by a trade-off. Stricter enforcement reduces the incentives for selective reporting but crowds out information search. We add to the literature that this trade-off between the quality and the quantity of information is overall robust to endogenizing enforcement but that it depends on the monitoring instruments in subtle

\footnotetext{
${ }^{6}$ When the firm is known to be informed, this effect leads to the classical unravelling result.

${ }^{7}$ See Matthews and Postlewaite (1985), Farell (1986), Shavell (1994), Dahm et al. (2009), Henry (2009), Polinsky and Shavell (2012), Kartik et al. (2017) and Schweizer (2017).

${ }^{8}$ As Kartik et al. (2017, p. 27) observe, "the martingale property of Bayesian updating implies that experts would gain nothing by acquiring information" when payoffs depend linearly on these beliefs.

${ }^{9}$ There is also suggestive evidence that such a relationship is not unrealistic. Grabowski et al. (2002) estimated a highly skewed distribution of returns (net present values) for new drug introductions. More precisely, the top decile of most successful new drugs accounted for a $52 \%$ of the total present value generated by all new drugs. This seems to suggest that the market rewards higher quality at a highly increasing rate. Moreover, it seems that this pattern has not changed over time. Grabowski and Vernon (1994) found a highly skewed distribution of returns for the 1980-1990 period. In this study, the top two deciles accounted for more than a $70 \%$ of the total net present value.
} 
ways 10 First, the disincentive effect arises from the mere existence of enforcement, even when monitoring is not stringent enough to avoid selective reporting. Second, when monitoring is stringent enough to avoid selective reporting, there are two opposing effects of raising the detection probability. On one hand, the confidence effect raises the opportunity costs of investment in information. But on the other hand, this effect applies less often, as the public is more frequently informed. We provide a condition on the shape of profit function which we call strictly increasing average quality, so that the function is responsive enough to the confidence effect and investment incentives decline.

Third, the nature of the relationship between the monitoring instruments might be different from the law enforcement setting. As explained before, in that model, increasing the probability of detection and maintaining an individual indifferent between committing or not the harmful act requires decreasing the fine. The monitoring instruments are substitutes in producing deterrence. This is because there is a deterrence effect of law enforcement, as a higher probability of detection deters the harmful act. In our model, this deterrence effect is mitigated by the confidence effect. The confidence effect makes withholding of evidence more attractive, because it raises the firm's payoffs when it is not detected. Again we provide a condition on the shape of the profit function (measured by an elasticity) under which the function is responsive enough to the confidence effect, so that increasing the probability of detection and maintaining an individual indifferent between committing or not the harmful act requires to increase the fine. The monitoring instruments are complements in producing deterrence ${ }^{11}$

Our second contribution is to investigate how the trade-off in monitoring should be resolved. The examples we have explored suggest that enforcement of disclosure rules is often welfare improving ${ }^{12}$ We present, however, an example with the following implications. First, it is important how mandatory disclosure rules are enforced. Some successful policies (that perfectly enforce mandatory disclosure) might generate lower welfare than laissez-faire, while other successful policies might induce higher welfare. Second, imperfect enforcement (in which some information remains concealed) might be better than both voluntary and mandatory disclosure. This is because the same monitoring policy must apply to different markets and stricter enforcement triggers a strong disincentive effect on investment in information in one of these markets. In that market investing in information and reporting it selectively is preferable to no investment in information at all. This conclusion does not rely on monitoring costs. Even if some additional resources

\footnotetext{
${ }^{10}$ Kartik et al. (2015) provide a related comparative statics result when the agent who sends a message bears a disclosure cost. Kartik et al. show that this leads to less disclosure. Their setting is different, however, as the agent is exogenously endowed with information.

${ }^{11}$ We also show that the condition on the elasticity is stronger than strictly increasing average quality.

${ }^{12}$ The fact that monitoring might reduce the amount of information available does not imply that stricter monitoring is undesirable. It is well known that the firm might have an incentive to invest in information when this is inefficient (see Jovanovic, 1982; Milgrom, 2008).
} 
for inspections are costless, it might not be beneficial to raise the probability of detection. Similarly, the optimal fine might be smaller than the largest possible fine, even though it requires fewer resources for inspections.

\section{Related Literature}

The law enforcement literature does not suggest that maximum penalties are always optimal (Garoupa, 1997; Polinsky and Shavell, 2000). Among the different reasons which may advocate for non-maximal penalties are marginal deterrence incentives (Mookherjee and Png, 1992), socially costly sanctions (Kaplow, 1990), differences in wealth among individuals (Polinsky and Shavell, 1991), imperfect information on the probability of apprehension (Bebchuk and Kaplow, 1992), risk-aversion (Polinsky and Shavell, 1979) or the possibility to engage in socially costly activities reducing the probability of detection (Malik, 1990). Lenient fines can also arise when penalties for collusion are dynamic and dynamic conditions for cartel stability are considered (Harrington, 2014). Since none of these papers contains a model of information transmission, these rationales for limits on fines are qualitatively different from the rationale we present.

Corts (2014), however, offers a rationale for finite expected penalties when false advertising claims signal unverifiable information about product quality. Optimal expected penalties might be finite, because when information on quality is expensive, society prefers the firm not to eliminate all uncertainty. Instead, it is desirable that the firm makes 'speculative claims' that sometimes turn out to be false. Too severe penalties deter the firm from making these claims. In contrast, we offer a model of selective reporting of verifiable information, rather than of false claims ${ }^{13}$ The drawback to high penalties is that they deter investment in information, rather than that they deter a firm to make claims that are likely, but not certain, to be true. Moreover, we explicitly model monitoring policies as a probability of detection in combination with a fine, rather than as an expected penalty. This allows us to derive the novel result that the fine and the probability of detection can be complements, which shows that the forces in our model are conceptionally different from those in all these previously reviewed papers ${ }^{14}$

The literature on disclosure rules does not suggest that mandatory disclosure rules are

\footnotetext{
${ }^{13}$ Piccolo et al. (2015) and Rhodes and Wilson (2017) offer related models of unverifiable information in which false advertising claims might deceive consumers about quality. In both models the optimal policy might not deter false advertising, because false advertising facilitates lower prices.

${ }^{14}$ In Dye (2017) the seller of an asset is liable to damages if it is detected that an estimate of the asset's value was withheld. Dye derives the related result that raising the probability that a fact finder detects selective reporting might induce the seller to disclose his estimate less often. The forces in Dye's model, however, are different from those in our model. In Dye's model a similar result applies to the damage multiplier (which is akin to the fine in our context), while raising the fine always induces less selective reporting in our model. Less closely related, Andreoni (1991) and Feess and Wohlschlegel (2009) find in a different model that deterrence might decrease in response to an increase in punishment.
} 
always better than voluntary ones. Polinsky and Shavell (2012) show that, because of the disincentive effect on endogenous information, welfare under the latter might be higher.15 We go beyond this result and show that the welfare effects of mandatory disclosure depend on how it is enforced. We also show that imperfect enforcement in which some information remains concealed might be optimal. The optimal effective disclosure rule might thus fall between the benchmarks of mandatory and voluntary disclosure.

It is also known that different disclosure rules have different effects on reporting and information search. Dahm et al. (2009) show that voluntary and compulsory clinical trial registries, which make the firm's decision to search for information observable, cannot solve the problem of selective reporting. They also show that a voluntary results database, which is a specific voluntary disclosure rule, leads to unravelling, because it allows an uninformed firm to prove that it has no information. The present paper differs from that paper by focussing on a mandatory disclosure rule that is successful when appropriately enforced, rather than a voluntary disclosure rule that is followed in order to avoid sceptical inference from the public.

This paper is organized as follows. The next section introduces our model. Section 3 characterizes its equilibria and establishes the existence of the trade-off in monitoring. Section 4 investigates the welfare effects of enforcement. Section 5 discusses robustness of our findings to alternative monitoring technologies. Section 6 concludes.

\section{The model}

\section{$2.1 \quad$ Agents}

Consider a firm (or seller) that sells a good to buyers (or the public). The quality of the good depends on the state of the world $v \in\{0,1\}$ and is ex-ante unknown. The prior probability that the good generates benefits $(v=1)$ is $q \in(0,1)$; with probability $1-q$ the good has side-effects $(v=0)$. To be concise, we refer to $q$ as measuring the (expected) quality of the good, rather than as the ex-ante likelihood of benefits or risk of harm.

\footnotetext{
${ }^{15}$ Relatedly, Di Tillio et al. (2015) show in a different model that it might be beneficial to allow for manipulation of information, because it might lead to more information in the system. Related forces appear in the sequential search model of Henry and Ottaviani (2017). Their earlier working paper allows for manipulation of information and shows that allowing some misreporting through a limited penalty is beneficial. In Kartik et al. (2017) mandatory disclosure rules would harm the decision maker. This implication of their model comes from the fact that adding more experts reduces each expert's incentive to invest in costly information. The reason for this is related to our result that successful monitoring affects the opportunity costs of information search, although the details differ. Dranove and Jin (2010) review additional reasons why mandatory disclosure does not always raise social welfare.
} 


\subsection{Information search by the seller}

Prior to offering the good for sale, the seller can invest in a test to provide information about product quality. Mimicking the outcomes of clinical trials, there are three possible outcomes (De Angeles et al., 2004). A positive test demonstrates that the seller's product is of high quality $(v=1)$, a negative one shows that the seller's product is of low quality $(v=0)$, and an inconclusive one does not provide new evidence.

Formally, the result of the test is denoted by $t$. With probability $x \in[0,1]$ the true state of the world is revealed and $t=v$. With probability $1-x$, the test is inconclusive and $t=\emptyset$. The test has a constant marginal cost $K_{x}>0$. The information revealed is hard evidence. This captures that a pharmaceutical firm cannot fabricate the entire evidence of clinical trials and indicate that treatment effects exist when they do not. The firm might, however, report results selectively. Denoting the seller's report or message by $m$, if $t=v$, the seller can publish or conceal the result of the test, i.e. $m \in\{v, \emptyset\}$. If $t=\emptyset$, the seller has to report $m=\emptyset$. We assume that the public cannot distinguish between a seller who invests in information and hides the result and a seller who does not invest in information; in both situations the public receives the message $m=\emptyset \cdot{ }^{16}$

\subsection{The seller's payoffs}

A central element of our model is the seller's profit function $\pi(q)$, which represents the equilibrium profits from the sales process $\sqrt{17}$ For most of our paper we consider a general function $\pi(q)$, rather than a specific interaction that gives rise to a specific functional form. This is so, because our equilibrium analysis depends only on the shape of $\pi(q)$. The following conditions define a class of functions that permits a sharp characterization 18

Assumption 1 (Monotonicity) The profit function $\pi(q)$ is weakly increasing in the quality $q$ of the product, with $\pi(0)<\pi(q)<\pi(1)$ for all $q \in(0,1)$ and $\pi(0)=0$.

Loosely speaking, Assumption 1 requires strict monotonicity at the endpoints of the interval and allows for weak monotonicity for intermediate values. This is in line with evidence

\footnotetext{
${ }^{16}$ This assumption is motivated by our leading example of pharmaceutical clinical trials. In an editorial Drazen et al. (2007) discuss legislation strengthening the FDA's regulatory authority and write (p. 1756) "The trial's sponsor, claiming proprietary rights, could keep all information about it, including its very existence, private. Thus, if a drug had important adverse effects, this information might never be made public." Notice also that the quote in footnote 5 describes a similar scope for manipulation.

${ }^{17}$ For our purpose it is sufficient to assume that this function depends directly on the (possibly updated) belief of the public about the quality of the good. This avoids additional notation capturing that the public takes actions based on $q$, say to buy or not to buy the firm's product, which in turn affects the profit function of the firm. Kartik et al. (2015) and (2017) make a similar assumption.

${ }^{18}$ Corts (2014) makes a similar assumption to our Assumption 1 in a different model. For analytical convenience we often assume implicitly that $\pi(q)$ is differentiable.
} 
from the antiulcer-drug market (Azoulay, 2002). Without such a monotonicity the seller has no incentive to search for information and to conceal negative information, precluding to study the problem of selective reporting. For simplicity of the exposition we also normalise $\pi(0)=0$. While we impose Assumption 1 throughout, the following properties impose more structure on the shape of $\pi(q)$ and will become important for some of our results.

Assumption 2 (Average quality) Let $\pi(q)$ be the profit function of the firm.

1. Average quality is bounded if for all $q \in(0,1)$ we have that

$$
\pi(q)<q \pi(1)
$$

2. Average quality is strictly increasing if for each $\zeta \in(0,1)$ and all $q$ we have that

$$
\zeta \pi(q)>\pi(\zeta q)
$$

Assumption $2 \sqrt{2}$ is related to the notions of concave and convex functions. The difference is that concavity and convexity are based on the monotonicity of the marginal slope, while it requires monotonicity of the average slope. The inequality in $(2)$ is equivalent to the requirement that the slope of the chord from the origin, given by $\pi(q) / q$, must be strictly increasing. This is weaker than strict convexity of $\pi(q)$, because $\pi(q)$ can have both convex and concave segments. Assumption 211 weakens Assumption 22,2, as it only requires that $\pi(q) / q$ is bounded by $\pi(1) \cdot{ }^{19}$ To see that Assumptions 1 and 2 are not unreasonable, it is instructive to consider the following examples.

Example 1 Suppose the firm sells to a single consumer. When the consumer buys the firm's product, profits $\hat{\pi}$ and consumer surplus $C S$ are generated. With probability $1-q$ the good is harmful $(v=0)$ and causes side-effects $H$, in addition to CS. Given a (possibly updated) belief $q$, the consumer buys the good if and only if she is sufficiently trustful that side-effects do not appear, that is,

$$
C S-(1-q) H \geq 0 \Leftrightarrow q \geq \underline{q} \equiv \frac{H-C S}{H}=1-\frac{C S}{H} .
$$

This implies that $\pi(q)=\hat{\pi}$ if $q \geq \underline{q}_{i}$ and $\pi(q)=0$ otherwise. This function fulfils neither Assumption 11 nor the two properties of Assumption 2 .

\footnotetext{
${ }^{19}$ Assumption 22 also implies Assumption 1 and is related to the notion of a strictly star-shaped function with respect to the origin (Bullen, 1998), which has appeared in the economic literature (see e.g. Landsberger and Meilijon, 1990; Chateauneuf et al., 2004; Armantier and Treich, 2009). We will see that Assumption 21 is a necessary and sufficient condition for the firm to be willing to invest in information when all test results must be reported.
} 
Example 2 Consider Example 1 but with a continuum of consumers with mass 1. With many pharmaceutical products there is uncertainty about the balance of benefits and harms. To focus on the former, let all consumers have the same level of potential side-effects $H=1$ but assume that they benefit to different degrees from treatment. Let $C S=z$ be distributed on the segment [0,1] according to the distribution function $G(z)$. By (3), only consumers with large treatment effects buy the drug. For a given $q$, the fraction of consumers that buys is $1-G(1-q)$ and profits are given by $\pi(q)=\hat{\pi}[1-G(1-q)]$. When $G(z)$ has a strictly positive density function, Assumption 1 holds. When $G(z)$ is concave (convex), $\pi(q)$ is convex (concave) and the two properties of Assumption 2 hold (do not hold). Concavity captures the realistic feature that moderate treatment effects (measured here by $C S$ ) are more likely to appear than strong effects (the median is smaller than 1/2).

\subsection{Enforcement of mandatory disclosure}

An agency monitors the firm. We think of monitoring as being similar to a situation in which the FDA controls a production plant searching for contamination problems of which the seller might be aware or not. If such problems are found, the agency tries to establish whether the firm was aware of them. Thus, monitoring might reveal information both on the firm's reporting behaviour and on the state of the world 20

Formally, when the seller does not reveal the state of the world (that is, $m=\emptyset$ ), the agency conducts a test at a constant marginal cost $K_{\rho}>0$. This test detects with probability $\rho \in(0,1)$ that the product is of low quality ${ }^{21}$ The agency only searches for negative information. This is motivated by our interest in selective reporting and the fact that the seller has no incentive to hide positive information. Denoting the outcome of the agency's report by $r \in\{0, \emptyset\}$, we have that

$$
\begin{aligned}
& \operatorname{Pr}(r=0 \mid v=0)=\rho=1-\operatorname{Pr}(r=\emptyset \mid v=0) \quad \text { and } \\
& \operatorname{Pr}(r=0 \mid v=1)=0=1-\operatorname{Pr}(r=\emptyset \mid v=1) .
\end{aligned}
$$

The agency might also learn about the firm's reporting behaviour. The agency discovers whether there was selective reporting when the test is successful but learns nothing when the test fails. Formally, when $r=0$ the firm's test result $t$ is also revealed. The

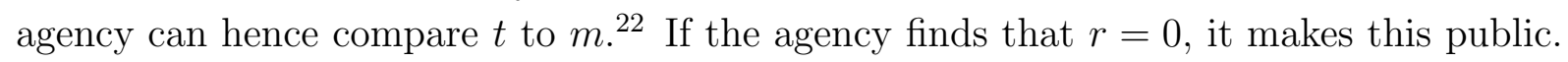
If, in addition, the agency finds evidence of selective reporting, a fine $F>0$ is imposed.

\footnotetext{
${ }^{20}$ In Section 5 we discuss the alternative assumption that the agency acquires information on reporting behaviour directly and does not learn about the state of the world.

${ }^{21}$ When $m \neq \emptyset$, the agency's test is redundant, as the firm's message is hard evidence. Assuming that the agency conducts tests with probability $\beta$ smaller than one would not change our results. It would suffice to make a change of variable so that $\rho^{\prime}=\beta \rho$ and rescale $K_{\rho}$.

${ }^{22}$ This best-case scenario for monitoring is the conservative assumption to make. The agency could learn the test result only with some probability but this case is less interesting. The reason is that our
} 


\section{$2.5 \quad$ Timing}

Once a monitoring policy $(F, \rho)$ is in place, the sequence of events is as follows:

1. The firm decides whether to conduct a test (the public does not observe this choice).

2. The seller sends a message $m$ to the buyer which is observed by the agency (if no test has been conducted, $m=\emptyset)$.

3. If $m=\emptyset$, the agency conducts its own research and obtains a report $r$, which is then made public (otherwise, $r=\emptyset$ ). If $r=0$ the agency also learns the firm's test result $t$ (if no test has been conducted, $t=\emptyset$ is revealed).

4. Depending on the outcomes of $m$ and $r$ as well as $t$ (provided $t$ was revealed), the agency decides whether to impose the fine on the firm, and the public updates her beliefs about the expected quality of the seller's product (that is, that the state of the world is $v=1$ ) from the prior $q$ to a posterior belief $\tilde{q}$.

5. The sales process captured through Assumption 1 takes place. The seller pays the fine, if the firm was monitored and a fine was imposed.

This game is solved by backward induction. Given that the public does not observe the investment decision in a test, she has to base her behaviour on her beliefs about the seller's choice. Moreover, the sales process when the state of the world has been revealed is a proper subgame of the extensive form game. The appropriate equilibrium concept is, hence, a Perfect Bayesian Equilibrium (PBE) in which all agents behave optimally, given their beliefs about the other's action and these beliefs are, at equilibrium, correct.

\section{The monitoring trade-off}

We investigate now the equilibria of the game, given an arbitrary monitoring policy $(F, \rho)$. As usual in this type of models, an informative and a non-informative equilibrium might coexist, depending on how expensive tests are. We investigate these possibilities in Subsections 3.1 and 3.2 , respectively. Subsection 3.3 builds on the equilibrium analysis and shows that monitoring policies must balance a trade-off.

\subsection{The informative equilibrium}

In an informative equilibrium the public expects the firm to invest in information and the beliefs of the public must be consistent with the firm's reporting behaviour. We start

main result that optimal monitoring might not be as strict as technically feasible is the less surprising, the less powerful the monitoring technology of the agency. 
with the latter and turn then to the firm's investment decision in information. Lastly, we summarize the informative equilibrium.

\subsubsection{The firm's reporting behaviour}

Suppose the firm invests in information. Denote the probability that the seller reports the test result honestly after a negative test by $y$. A general formulation of the firm's reporting behaviour that allows for mixing between reporting and concealing evidence after a negative test is defined as follows

$$
m(y)=\left\{\begin{array}{lll}
1 & \text { if } & t=1 \\
\emptyset & \text { if } & t=\emptyset \\
0 & \text { with probability } y \text { if } & t=0 \\
\emptyset & \text { with probability } 1-y \text { if } & t=0
\end{array} .\right.
$$

Notice that (4) includes selective reporting $m^{S R}$ and honest reporting $m^{H R}$ of test results for $y=0$ and $y=1$, respectively.

The posterior beliefs of the public are then given by

$$
\tilde{q}=\left\{\begin{array}{ll}
\operatorname{Pr}(v=1 \mid m=0)=0 & \text { if } m=0 \\
\operatorname{Pr}(v=1 \mid m=\emptyset \wedge r=0)=0 & \text { if } m=\emptyset \wedge r=0 \\
\operatorname{Pr}(v=1 \mid m=1)=1 & \text { if } m=1 \\
\operatorname{Pr}(v=1 \mid m=\emptyset \wedge r=\emptyset)=\tilde{q} \emptyset & \text { if } m=\emptyset \wedge r=\emptyset
\end{array} .\right.
$$

The subindex $\emptyset$ in $\tilde{q}_{\emptyset}$ indicates that the public has not received new information, as neither the firm nor the agency reveal the state of the world. This belief is given by

$$
\tilde{q}_{\emptyset} \equiv \frac{\operatorname{Pr}(m=\emptyset \mid v=1) \operatorname{Pr}(r=\emptyset \mid v=1) \operatorname{Pr}(v=1)}{\operatorname{Pr}(m=\emptyset \wedge r=\emptyset)}=\frac{q(1-x)}{1-x q-(1-q)[\rho+x y(1-\rho)]}
$$

and has the following properties. First, the higher the quality of the search technology $x$, the more pessimistic the public, as $\partial \tilde{q}_{\emptyset} / \partial x<0$; in the extreme case of $x=1$, it is known that the firm is informed and the classical unravelling argument obtains. Our focus, however, is on situations in which the test might be inconclusive, so that $\tilde{q}_{\emptyset}>0$. Second, the more pessimistic the prior $q$, the lower the updated assessment $\partial \tilde{q}_{\emptyset} / \partial q>0$. Third, $\partial \tilde{q}_{\emptyset} / \partial y>0$ holds. The higher the likelihood of selective reporting, the more pessimistic the public. If the firm is suspected to report selectively with a higher probability (and so $y$ declines) and no evidence is published, then the public infers that it becomes more likely that information has been withheld and that the product is of low quality $(v=0)$. We call this the scepticism effect of selective reporting. In the extreme cases of selective reporting $(y=0)$ and honest reporting $(y=1)$, respectively, we obtain

$$
\tilde{q}_{\emptyset}^{S R} \equiv \frac{q(1-x)}{1-x q-\rho(1-q)} \quad \text { and } \quad \tilde{q}_{\emptyset}^{H R} \equiv \frac{q}{1-\rho(1-q)} .
$$


Lastly, $\partial \tilde{q}_{\emptyset} / \partial \rho>0$ holds. The better the quality of monitoring, the more optimistic the public becomes. We call this the confidence effect of monitoring. As we will see, this effect induces some interesting forces to appear in our model.

Suppose the seller invests in information and the test is negative. If the seller reports $m=0$ truthfully, then profits are zero and the firm is not fined. On the other hand, concealing negative evidence risks being detected by the agency. If detected, it becomes known that the product is of low quality and in addition the fine $F$ is imposed. If not detected, the public anticipates the frequency of honest reporting $y$ and profits are $\pi\left(\tilde{q}_{\emptyset}\right)$. Thus, the firm prefers to reveal rather than conceal a negative test if and only if

$$
(1-\rho) \pi\left(\tilde{q}_{\emptyset}\right) \leq \rho F .
$$

Notice that without appropriate enforcement (7) cannot hold. Under laissez faire, where $\rho=0$, the expected fine is zero. The Monotonicity Assumption 1 implies then that (7) does not hold. Consequently, the seller only discloses favourable information about product quality. The comparison in (7) implies the following result.

Lemma 1 For any probability of detection $\rho>0$, there exists a minimum penalty

$$
\tilde{F}_{y}(q, \rho) \equiv \frac{1-\rho}{\rho} \pi\left(\tilde{q}_{\emptyset}\right)
$$

such that for any $F \geq \tilde{F}_{y}(q, \rho)$, the seller discloses all test results.

This lemma shows that there always exist monitoring policies $(F, \rho)$ that can avoid selective reporting. Because of the Monotonicity Assumption 1 , the minimum penalty $\tilde{F}$ is increasing in $\tilde{q}_{\emptyset}$. Thus the properties of the belief $\tilde{q}_{\emptyset}$ in (5) affect the minimum penalty $\tilde{F}$ and hence the success of monitoring. In particular, we have the following.

First, because of the scepticism effect $\partial \tilde{q}_{\emptyset} / \partial y>0$, the minimum penalty $\tilde{F}$ is increasing in $y$. This is so, because the less the firm is expected to conceal information, the higher the benefit from withholding evidence. A consequence of this property is that both pure strategy reporting and mixed reporting can appear. To see this notice that in a selective reporting equilibrium both $y=0$ and $F \leq \tilde{F}_{0}(q, \rho)$ must hold, while the requirements in a honest reporting equilibrium are that $y=1$ and $F \geq \tilde{F}_{1}(q, \rho)$. The scepticism effect $\partial \tilde{q}_{\emptyset} / \partial y>0$ implies that $\tilde{F}_{0}(q, \rho)<\tilde{F}_{1}(q, \rho)$, provided the profit function is strictly monotone (Figure 1 below provides an example). Consequently, for some combinations of the prior $q$ and monitoring policies $(F, \rho)$ a pure strategy equilibrium at the reporting stage does not exist. It is neither an equilibrium to report negative information always honestly, nor is it an equilibrium to report it always selectively. A mixed-strategy, however, in which the seller sometimes conceals and sometimes reveals negative information allows to trade-off the frequency of being caught with the benefits from holding back negative information 23

\footnotetext{
${ }^{23}$ Consider a monitoring policy $(F, \rho)$ with $F \in\left(\tilde{F}_{0}, \tilde{F}_{1}\right)$ and assume that $d \pi / d q>0$ holds for the
} 


\subsubsection{The firm's investment in information}

The seller's expected profits from searching for information are,

$$
\begin{aligned}
\Pi_{t}(q, y)= & x q \pi(1)+[(1-x) q+(1-q)(1-\rho)(1-x y)] \pi\left(\tilde{q}_{\emptyset}\right) \\
& -(1-q) \rho x(1-y) F-x K_{x} .
\end{aligned}
$$

The first three terms represent the profits of the firm and depend on what is reported. With probability $x q$ there will be a positive test which will be revealed and the public will be certain that the good generates benefits. In the remaining cases, however, the test will be negative or inconclusive and profits depend on the reporting strategy of the firm, which are described by $y$ and in equilibrium will be anticipated by the public. For example, if the firm reports selectively so that $y=0$, then only the agency might inform the public that the product is harmful. In this case the public will be certain that the good generates side-effects and this happens with probability $(1-q) \rho$. In a fraction $x$ of these events information was withheld and the fine is imposed. In all other cases no information is revealed and, since $y=0$, the public's belief is $\tilde{q}_{\emptyset}^{S R}$. On the other hand, if the firm reports honestly so that $y=1$, then the public's belief is either $\tilde{q}_{\emptyset}^{H R}$ or 0 and the fine is never imposed. Lastly, mixing between reporting selectively and honestly by setting $y \in(0,1)$ yields a combination of the profits described for the previous two cases. The last term represents the costs of the test.

The seller's expected profits from not searching for information are,

$$
\Pi_{\neg t}(q)=[1-(1-q) \rho] \pi\left(\tilde{q}_{\emptyset}\right) .
$$

Since the seller is expected to invest and to report honestly with some probability $y$, profits depend on the interplay between the confidence and scepticism effects via the belief $\tilde{q}_{\emptyset}$. In addition, there is the risk that monitoring detects low quality.

The seller invests in the test if and only if

$$
\Pi_{t}(q, y)-\Pi_{\neg t}(q)>0 \Leftrightarrow K_{x}<\mathbb{K}_{t}(q, \rho, F, y),
$$

where

$$
\begin{aligned}
\mathbb{K}_{t}(q, \rho, F, y) \equiv & q\left[\pi(1)-\pi\left(\tilde{q}_{\emptyset}\right)\right] \\
& -(1-q)(1-\rho) y \pi\left(\tilde{q}_{\emptyset}\right)-(1-q) \rho(1-y) F .
\end{aligned}
$$

\subsubsection{The informative equilibrium}

We summarize the preceding two subsections as follows.

relevant values for $q$. The seller is indifferent between reporting honestly and concealing negative evidence if the buyer holds a belief $\hat{y}$ such that $F=\tilde{F}_{\hat{y}}(q, \rho)$. Notice that, since $\tilde{F}$ is a continuous function of $y$, we can apply Bolzano's Theorem and conclude that such a belief $\hat{y}$ exists. 
Proposition 1 (Informative equilibrium) With the monitoring policy $(F, \rho)$, there exists a PBE in which the seller invests in information search, provided the test is cheap enough, that is, $K_{x} \leq \mathbb{K}_{t}(q, \rho, F, y)$, where $\mathbb{K}_{t}(q, \rho, F, y)$ is defined in (12). In this equilibrium, the firm's reporting behaviour is as follows:

(a) If the monitoring technology is weak, that is, $F \leq \tilde{F}_{0}(q, \rho)$, then the seller reports selectively.

(b) If the strictness of the monitoring technology is intermediate, that is, $F \in\left[\tilde{F}_{0}, \tilde{F}_{1}\right]$, then the seller mixes between honest and selective reporting.

(c) If the monitoring technology is powerful, that is, $F \geq \tilde{F}_{1}(q, \rho)$, then the seller reports honestly.

The reporting behaviour described in part (a) might appear cynical. But it rationalizes behaviour in line with a statement by Representative Henry Waxman (D-CA) at a hearing: "The pharmaceutical industry has systematically misled physicians and patients by suppressing information on their drugs...," see Couzin (2004, p. 1695). In contrast, the reporting behaviour in part (c) captures the ideal described in De Angelis et al. (2004, p. 477): "The interests of the sponsor or authors notwithstanding, anyone should be able to learn of any trial's existence and its important characteristics."

\subsection{The non-informative equilibrium}

In a non-informative equilibrium the firm does not invest in information and this is correctly anticipated by the public. Hence, the scepticism effect is not present. The confidence effect is present, however, since it is known that the agency will monitor the firm. The beliefs of the buyer are then given by $\tilde{q}_{\emptyset}^{H R}$ in $(6)$. Hence, if the firm does not deviate and does not invest, expected profits are given by $(10)$ with $\tilde{q}_{\emptyset}$ replaced by $\tilde{q}_{\emptyset}^{H R}$.

Expected profits from search depend on whether the most profitable deviation involves selective or honest reporting. For $F \geq \tilde{F}_{1}$, the most profitable deviation involves honest reporting $y=1$, while selective reporting $y=0$ is optimal for $F \leq \tilde{F}_{1}$. In both cases, however, since the firm is not expected to search, absent new information, the beliefs of the buyer are given by $\tilde{q}_{\emptyset}^{H R}$. Thus, expected profits from search are given by (9), with $y=1$ and $\tilde{q}_{\emptyset}=\tilde{q}_{\emptyset}^{H R}$ when $F \geq \tilde{F}_{1}$ and $y=0$ and $\tilde{q}_{\emptyset}=\tilde{q}_{\emptyset}^{H R}$ otherwise. Using $(8)$ we see that these expected profits are continuous at $F=\tilde{F}_{1}$.

Thus, the seller invests in the test if and only if

$$
\Pi_{t}(q)-\Pi_{\neg t}(q)>0 \Leftrightarrow K_{x}<\mathbb{K}_{\neg t}(q, \rho, F, y),
$$


where $\mathbb{K}_{\neg t}(q, \rho, F, y)$ is equal to $\mathbb{K}_{t}(q, \rho, F, y)$ as defined in $(12)$, with $y=1$ and $\tilde{q}_{\emptyset}=\tilde{q}_{\emptyset}^{H R}$ when $F>\tilde{F}_{1}$ and $y=0$ and $\tilde{q}_{\emptyset}=\tilde{q}_{\emptyset}^{H R}$ otherwise. ${ }^{24}$ Again, using (8) we see that the threshold $\mathbb{K}_{\neg t}(q, \rho, F, y)$ is continuous at $F=\tilde{F}_{1}$.

From the preceding follows that a non-informative equilibrium requires the test to be sufficiently expensive. We record this with the following result.

Proposition 2 (Non-informative equilibrium) With the monitoring policy $(F, \rho)$, there exists a PBE in which the seller does not invest in information search, provided the test is expensive enough, that is, $K_{x} \geq \mathbb{K}_{\neg t}(q, \rho, F, y)$, where $\mathbb{K}_{\neg t}(q, \rho, F, y)$ is defined after (13).

\subsection{The trade-off between the quality and the quantity of infor- mation}

As explained in the Introduction, it well known that when enforcement is exogenous, a change from voluntary to mandatory disclosure reduces the incentives to invest in information. Our model captures this by setting $\rho=0$ and comparing the cost threshold $\mathbb{K}_{t}$ in (12) for $y=0$ (voluntary disclosure) to $y=1$ (mandatory disclosure). Since this threshold is higher for the former than for the latter, there is a trade-off between the quality and the quantity of information. It is also well known that this disincentive effect has the potential to be very strong. In our model the precise condition for the disincentive effect not to crowd out investment in information completely is Assumption 21. We suppose in the remainder of this section that this assumption holds. We show that the trade-off between the quality and the quantity of information is overall robust to endogenizing enforcement but that it depends on the monitoring instruments in subtle ways. ${ }^{25}$

We start with the effect of stricter monitoring on the quality of information. Consider an increase in the fine. Notice first that if the fine is initially low enough and the increase is large enough, then comparison of cases (a) and (c) in Proposition 1 implies an increase in the quality of information. For smaller increases, it is instructive to consider again the indifference condition between honest and selective reporting in (7). Raising the fine $F$ and maintaining indifference requires raising $\pi\left(\tilde{q}_{\emptyset}\right)$, and so the probability of honest reporting $y$ must increase, making the public less sceptical.

Consider now the indifference condition (7) and an increase in the detection probability. First, there is the well-known deterrence effect of law enforcement, as the expected fine increases. But there is also a countervailing second effect. More frequent monitoring triggers the confidence effect, making the public more optimistic. When the confidence

\footnotetext{
${ }^{24}$ Notice that $\mathbb{K}_{\neg t}(q, \rho, F) \leq \mathbb{K}_{t}(q, \rho, F)$. For any combination of parameter values, there is a PBE. But it is possible that an informative and a non-informative equilibrium coexist. Our results, however, do not depend on a particular equilibrium selection.

${ }^{25}$ We thank a referee for detailed comments that helped us to clarify our contribution to the previous literature and to simplify considerably the exposition of this subsection.
} 
effect is very strong, maintaining indifference requires that the firm lowers the probability of honest reporting $y$. The overall effect is hence ambiguous and the precise condition for an increase in the quality of information is the same as in the following Proposition.

This proposition shows that the relationship between the probability of detection $\rho$ and the fine $F$ does not have to be substitutive but might be complementary. We say that $\rho$ and $F$ are substitutes if an increase in the probability of punishment lowers the minimum fine needed to ensure full disclosure (for a fixed level of $y$ ), i.e., $\tilde{F}_{y}(q, \rho)$ is decreasing in $\rho$. We say that $\rho$ and $F$ are complements when the opposite is true and $\tilde{F}_{y}(q, \rho)$ is increasing in $\rho$. A complementary relationship implies that starting from a situation in which monitoring provides sufficient incentives to report honestly, an increase in $\rho$ might lead to insufficient incentives and thus to a decline in the quality of information. The proposition specifies a condition for a complementary relationship. The discussion following the proposition provides then an example showing that this condition can be satisfied under our assumptions. The possibility of a complementary relationship stands in sharp contrast to the standard law enforcement setting and shows that our setting is qualitatively different. 26

Proposition 3 The probability $(\rho)$ and severity $(F)$ of punishment are substitutes if and only if

$$
\left.\frac{\tilde{q}_{\emptyset}}{\pi\left(\tilde{q}_{\emptyset}\right)} \frac{d \pi}{d q}\right|_{\tilde{q}_{\emptyset}}<\frac{1-x q-(1-q)[\rho+x y(1-\rho)]}{\rho(1-\rho)(1-q)(1-x y)} .
$$

Proof: See Appendix A.1.

This Proposition relates the existence of a complementary relationship to Assumption 22. This is so, because on the left hand side of (14) we have the elasticity of the profit function with respect to $q$. Strictly increasing average quality is equivalent to this expression being larger than one for all values of $q$. Since the right hand side is also strictly larger than one, condition (14) holds when $\pi(q)$ is responsive enough, so that the confidence effect overwhelms the deterrence effect. Consider the profit function $\pi(q)=q^{3} \cdot{ }^{27}$ Figure 1 displays the minimum fine as a function of $\rho$ (Lemma 1) when $\beta=3$ and $x=q=0.2$ for $y=0$ (selective reporting) and for $y=1$ (honest reporting). It illustrates a complementary relationship for a large interval of intermediate values of $\rho$.

Consider now the effect of stricter monitoring on the quantity of information. For simplicity, the next proposition focusses on either honest or selective reporting ${ }^{28}$

\footnotetext{
${ }^{26}$ In the standard law enforcement setting the criminal's payoff from committing a harmful act does not depend on a belief of the public that he is liable. This prevents the confidence effect from operating, the right hand side of $(8)$ declines with $\rho$, and $\rho$ and $F$ are substitutes.

${ }^{27}$ This function arises from Example 2 when $\hat{\pi}=1$ and $G(z)=1-(1-z)^{3}$. The latter is a special case of the Kumaraswamy distribution, where one parameter is equal to one and the other is three.

${ }^{28}$ The following result focusses on the informative equilibrium of Proposition 1. A similar result can
} 


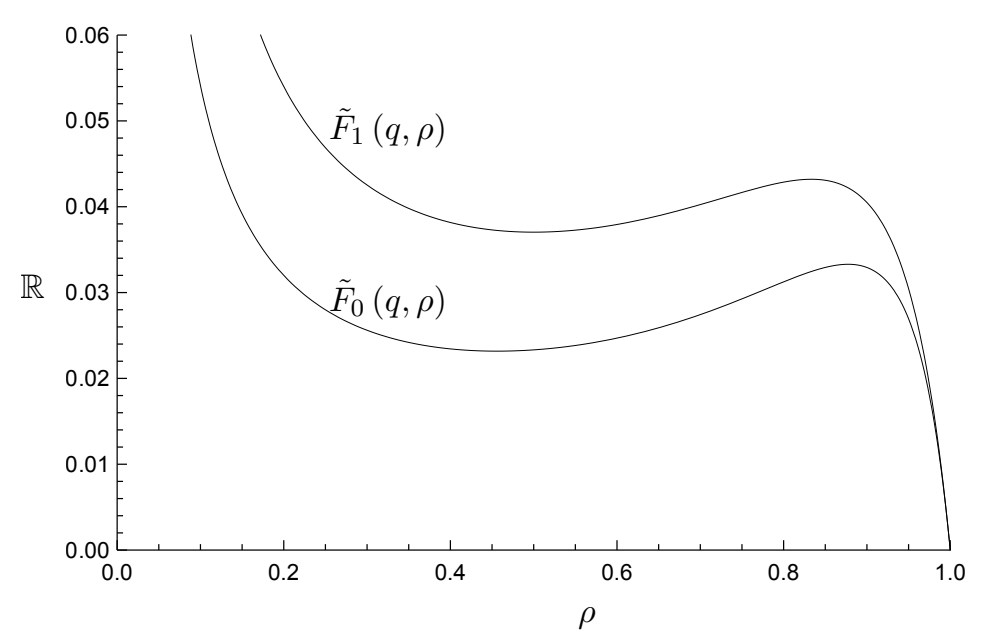

Figure 1: The minimum fine as a function of $\rho$ when $\pi(q)=q^{3}$ and $x=q=0.2$

Proposition 4 Enforcement decreases the incentives to invest in information. More precisely, for $y \in\{0,1\}$ :

1. If the monitoring technology is weak, that is, $F \leq \tilde{F}_{0}(q, \rho)$, then both raising the fine and the probability of detection strictly decreases the incentives to invest;

2. If the monitoring technology is powerful, that is, $F \geq \tilde{F}_{1}(q, \rho)$, then raising the fine does not affect the incentives to invest; these incentives decrease strictly when the probability of detection is raised if and only if Assumption 202 holds.

Proof: See Appendix A.2.

The first part of this proposition implies that unsuccessful enforcement is not only costly because it wastes resources on inspections, but also because both monitoring instruments reduce the incentives to invest in information. On one hand, selective reporting risks detection and hence investment incentives decrease with the expected fine. On the other hand, the confidence effect increases the opportunity costs of investment. The second part of Proposition 4 implies that it is important how successful enforcement is enforced. Different combinations of detection probability and fine trigger different disincentive effects. If enforcement is successful, then the fine is never imposed and does not

be obtained for the non-informative equilibrium of Proposition 2. For example, under Assumption $2 \sqrt{2}$ raising the probability of detection, reduces the cost interval $\left[0, \mathbb{K}_{t}(q)\right]$ in which search takes place in an informative equilibrium and increases the interval $\left[\mathbb{K}_{\neg t}(q), \infty\right)$ in which search does not take place in a non-informative equilibrium. Consequently, the incentives for information search are reduced through stricter monitoring independently of equilibrium selection (if there is multiplicity). 
affect equilibrium behaviour. Raising the probability of detection, however, has subtle effects. On one hand, it triggers the confidence effect. But on the other hand, this confidence effect applies less often, as the public is more frequently informed. If $\pi(q)$ has strictly increasing average quality, then the shape of $\pi(q)$ amplifies the confidence effect enough to outweigh this second effect and investment incentives decline.

\section{Imperfect enforcement can be optimal}

Section 3 describes the trade-off in monitoring but does not evaluate how it should be resolved. We present now an example with the following implications ${ }^{29}$ First, because of the subtleties described in Proposition 4, it is important how mandatory disclosure rules are enforced. With some successful policies (that perfectly enforce mandatory disclosure), welfare might be lower than with laissez-faire, while with others it might be higher. Interestingly, the policy generating the highest welfare might not require the lowest resource costs for inspections. Second, imperfect enforcement (in which some information remains concealed) might be better than both voluntary and mandatory disclosure. The logic for this does not rely on monitoring costs. Even if some additional inspections are costless, it might not be beneficial to raise the probability of detection. Similarly, the optimal fine might be smaller than the largest possible fine, even though the latter requires fewer resources for inspections.

Consider a market as described in Example 1 but with two consumers $i=A, B$. As in Example 2, the firm receives the same profit $\hat{\pi}$ when either consumer buys the product. Both consumers obtain the same consumer surplus $C S$ but differ in the potential sideeffects $H_{i}$. Consumer $B$ 's potential side-effects are more severe, that is, $H_{A}<H_{B}$. He is less trustful in the sense of the threshold in (3), as $\underline{q}_{A}<\underline{q}_{B}{ }^{30}$ Assume that initially $q<\underline{q}_{A}$ holds, so that based on the prior $q$ consumers do not buy the product. To illustrate that our assumptions are consistent, we provide the following set of parameter values. Let $H_{A}=900, H_{B}=1400, C S=500, \hat{\pi}=500, q=0.4$, and $x=0.6$. This implies that $\underline{q}_{A}=0.44$ and $\underline{q}_{B}=0.64$. We also assume that the firm's test is costless, that is, $K_{x}=0$, while monitoring has a marginal cost of $K_{\rho}=450$.

\footnotetext{
${ }^{29}$ Our earlier working paper Dahm et al. (2016) considers a general setting and defines the maximisation problem of a social planner choosing the optimal monitoring policy. Unfortunately, it turns out that the planner's problem is not well behaved and analysis of first-order conditions might not identify the optimal monitoring policy.

${ }^{30}$ This implies that $\pi(q)=2 \hat{\pi}$ if $q \geq \underline{q}_{B}, \pi(q)=\hat{\pi}$ if $\underline{q}_{B}>q \geq \underline{q}_{A}$ and $\pi(q)=0$ otherwise. This function fulfils neither Assumption 1 nor the two properties of Assumption 2 and thus shows the role these assumptions play in our analysis. On one hand, they provide the firm with a strict incentive to conceal negative information. This applies only to Subsection 4.1 and does not affect the firm's incentives to invest in information. On the other hand, in the following example Assumption 2 does not hold and the disincentive effect of monitoring on information search is very strong.
} 
The regulator chooses a monitoring policy $(F, \rho)$ to maximize social welfare, defined as the sum of the firm's profits and consumer surplus, net of expected side-effects. We will organise our exploration of policies along two dimensions. First, enforcement can be unsuccessful or successful in securing honest reporting. Second, enforcement triggers the confidence effect, making consumers more trustful. Depending on the strength of this effect, one or both consumers might remain mistrustful and only buy the product when the test shows that there are no side-effects or become trustful so that they buy unless side-effects are discovered.

\subsection{Unsuccessful enforcement}

Consider a policy $(F, \rho)$ such that $F<\tilde{F}_{1}(q, \rho)$ and the firm has a strict incentive to report selectively. Assume that $\rho$ is small enough so that $\tilde{q}_{\emptyset}^{S R}<\underline{q}_{A}$ holds, implying that trade requires proof that there are no side-effects ${ }^{31}$ This can provide incentives for the firm to conduct a test, as testing is costless, provided the expected fine is small enough. The threshold in (12) becomes

$$
\mathbb{K}_{t}=2 q \hat{\pi}-(1-q) \rho F
$$

and social welfare of unsuccessful enforcement (UE) follows

$$
\mathbb{W}^{U E}=2 x q(C S+\hat{\pi})-\rho K_{\rho}
$$

because trade requires proof that there are no side-effects. Thus the optimal unsuccessful enforcement policy is laissez-faire (LF), which sets $\rho=0$ and hence $F<\tilde{F}_{1}(q, 0){ }^{32}$ For the above specified set of parameter values, laissez-faire induces a unique informative selective reporting equilibrium with welfare of $\mathbb{W}^{L F}=480$, as $\tilde{q}_{\emptyset}^{S R}=0.21$ and hence $\mathbb{K}_{t}=400$.

\subsection{Perfect enforcement with weak confidence effect}

Consider a policy $(F, \rho)$ such that $F \geq \tilde{F}_{1}(q, \rho)$ and the firm has an incentive to report honestly. Moreover, assume that $\tilde{q}_{\emptyset}^{H R}<\underline{q}_{A}$; there is a weak confidence effect (WCE). As in Subsection 4.1, both consumers do not buy, unless there is proof that there are

\footnotetext{
${ }^{31}$ For policies raising the belief to $\tilde{q}_{\emptyset}^{S R} \geq \underline{q}_{A}$ there is more trade and thus social welfare is different from the expression (16) below. These policies, however, are worse than successful policies with the same detection probability, because some side-effects are avoided when the firm discloses negative test results. Successful policies are considered next.

${ }^{32}$ If $\tilde{q}_{\emptyset}^{H R}<\underline{q}_{A}$, then $\mathbb{K}_{t}=\mathbb{K}_{\neg t}$ and a non-informative equilibrium does not exist. For more powerful policies the threshold $\mathbb{K}_{\neg t}$ becomes negative and such an equilibrium exists. Such a non-informative equilibrium, however, is similar to the one arising under a successful policy with the same detection probability. Successful policies are considered next.
} 
no side-effects. As under laissez-faire, this implies that there might be incentives for the firm to conduct a test. Welfare, however, is always lower than under laissez-faire, because trade requires a positive test and there are monitoring costs. For completeness we remark that for the above specified set of parameter values, for example, the policy $F_{W C E}=5000$ and $\rho_{W C E}=0.09$ implements mandatory disclosure with weak confidence effect. For this policy welfare is $\mathbb{W}^{W C E}=439$, as $\tilde{q}_{\emptyset}^{H R}=0.42$ and hence $\mathbb{K}_{t}=400$.

\subsection{Perfect enforcement with strong confidence effect}

Consider a policy $(F, \rho)$ such that $F \geq \tilde{F}_{1}(q, \rho)$ and the firm has an incentive to report honestly. Moreover, assume that $\underline{q}_{B} \leq \tilde{q}_{\emptyset}^{H R}$; there is a strong confidence effect (SCE). Both consumers become trustful and buy, unless side-effects are discovered. This implies that the firm gains nothing from testing. Formally, the cost threshold for investment is the same for an informative and a non-informative equilibrium. As this threshold is negative, only the non-informative equilibrium exists. Consumers benefit from the product when it is of high quality. They experience side-effects when quality is low and monitoring does not reveal information. Welfare is hence given by

$$
\mathbb{W}^{S C E}=2 q(C S+\hat{\pi})+(1-q)(1-\rho)\left[2(C S+\hat{\pi})-H_{A}-H_{B}\right]-\rho K_{\rho} .
$$

The cheapest such policy sets $\underline{q}_{B}=\tilde{q}_{\emptyset}^{H R}$. For the above specified set of parameter values this policy is $F_{S C E}=300$ and $\rho_{S C E}=0.63$. Since $\tilde{q}_{\emptyset}^{H R}=0.64$, we have $\mathbb{K}_{\neg t}=-22.5$ and there is a unique non-informative equilibrium with welfare $\mathbb{W} S C E=451$.

\subsection{Perfect enforcement with intermediate confidence effect}

Consider a policy $(F, \rho)$ such that $F \geq \tilde{F}_{1}(q, \rho)$ and the firm has an incentive to report honestly. Moreover, assume that $\underline{q}_{A} \leq \tilde{q}_{\emptyset}^{H R}<\underline{q}_{B}$; there is an intermediate confidence effect (ICE). Consumer $A$ buys unless the test proves that there are side-effects, while consumer $B$ does not buy unless the test proves that there are no side-effects. This intermediate level of trade in the absence of further information implies that there might be gains from investment in information. Indeed, we have that

$$
\mathbb{K}_{t}=\mathbb{K}_{\neg t}=[q-(1-q)(1-\rho)] \hat{\pi}
$$

which will be positive, provided the prior $q$ and the detection probability $\rho$ are high enough. When the firm's test is successful both consumers trade. Otherwise only consumer $A$ buys, provided no side-effects are discovered. Hence, welfare follows

$$
\begin{aligned}
\mathbb{W}^{I C E}= & 2 x q(C S+\hat{\pi})+(1-x) q(C S+\hat{\pi}) \\
& +(1-q)(1-x)(1-\rho)\left(C S+\hat{\pi}-H_{A}\right)-\rho K_{\rho} .
\end{aligned}
$$


$\mathbb{W}^{I C E}$ might be higher than $\mathbb{W}^{S C E}$, because the strong disincentive effect on information search is avoided, the firm invests in information and reports honestly. In addition, monitoring costs are lower and the strong potential side-effects $H_{B}$ are avoided, as consumer $B$ is not trustful enough to buy without further information. $\mathbb{W}^{I C E}$ might be higher than $\mathbb{W}^{L F}$, because consumer $A$ is trustful enough to buy and the firm reports side-effects honestly. For the above specified set of parameter values the cheapest such policy is $F_{I C E}=990$ and $\rho_{I C E}=0.34$. Since $\tilde{q}_{\emptyset}^{H R}=0.5$, we have $\mathbb{K}_{t}=0.07$ and there is a unique informative honest reporting equilibrium. Welfare is $\mathbb{W}^{I C E}=505$.

\subsection{Imperfect enforcement tolerating some selective reporting}

The best policy considered so far induces perfect enforcement (with intermediate confidence effect; Subsection 4.4). But imperfect enforcement in which some information remains concealed, can also be optimal. To see this, suppose that in addition to the firm already considered, there is another firm operating in a different market. Both firms are subject to the same enforcement policy. Hence there are no additional monitoring costs. ${ }^{33}$ We show that the policy described in Subsection 4.4 remains optimal. With this policy with intermediate confidence effect, there is an informative selective reporting equilibrium in the second market. Stricter enforcement leads to a non-informative equilibrium generating lower social welfare in that market, so that overall welfare is also lower.

To see that this can be achieved, assume that unless specified otherwise the above specified set of parameter values apply also to the second market. Suppose in the second market profits $\hat{\pi}_{2}=560$ are slightly higher than in the first market, so that $F<\tilde{F}_{1}(q, \rho)$. Consequently, the second firm has a strict incentive to report selectively. Assume there is a consumer $C$ with $C S_{C}=2450$ and $H_{C}=5000$ so that $\underline{q}_{C}$ is just above the updated belief for the policy with intermediate confidence effect, that is $\tilde{q}_{\emptyset}^{H R}<\underline{q}_{C}$. Consequently, when consumer $C$ anticipates selective reporting, trade requires proof that there are no side-effects and an informative selective reporting equilibrium in the second market exists. In the example, $\tilde{q}_{\emptyset}^{S R}=0.29, \underline{q}_{C}=0.51$, and hence $\mathbb{K}_{t}=25$. The equilibrium is unique and welfare is $\mathbb{W}_{2}^{S R}=722$. Overall welfare in the two markets is 1227 .

Other enforcement policies do not yield higher overall welfare. Consider stronger enforcement that raises both the fine and the detection probability a little bit, so that it eradicates selective reporting and induces consumer $C$ to be trustful unless side-effects are discovered. In the example the cheapest such policy is $F=1000$ and $\rho=0.36$. A strong disincentive effect applies, the firm gains nothing from testing and only a non-informative equilibrium exists. Hence, overall welfare is only 933. The informative selective reporting equilibrium generates higher welfare, because by generating less trade it avoids side-effects.

\footnotetext{
${ }^{33}$ Alternatively, assume that monitoring in each market implies a cost of $\rho K_{\rho}^{\prime}$, where $2 K_{\rho}^{\prime}=K_{\rho}$. This yields the same total welfare in the two markets as our formulation.
} 
This ranking does not change if the additional resources for inspections are costless. Consider now the policy $F_{W C E}=5000$ and $\rho_{W C E}=0.09$ implementing mandatory disclosure with weak confidence effect in the first market. Raising the fine further eventually implements mandatory disclosure in both markets, so that trade requires a positive test. Overall welfare is only 1161. Thus, the optimal fine might be smaller than the largest possible fine, even though less resources for inspections are required ${ }^{34}$

\section{$5 \quad$ Alternative monitoring technologies}

Our analysis postulates a specific monitoring technology inspired by the FDA inspecting production plants and searching for, say, contamination problems. Two assumptions seem important. First, monitoring might reveal information both on the firm's reporting behaviour and on the state of the world. Second, the agency only searches for information on the state of the world in which quality problems appear.

The main forces of our model are still present if the agency focusses more on the discovery of selective reporting than on the state of the world. To see this consider the extreme assumption that it does not search for information on the state of the world at all. If the firm reports selectively $(y=0)$, the outcome of the agency's report either discovers this $(r=0)$ or discovers nothing $(r=\emptyset)$, with probabilities

$$
\operatorname{Pr}(r=0 \mid v=0 \wedge y=0)=\rho=1-\operatorname{Pr}(r=\emptyset \mid v=0 \wedge y=0) .
$$

If the firm reports honestly or does not invest in information, then the agency learns nothing from monitoring. Under these assumptions the posterior beliefs of the public are given by (5), where $\tilde{q}_{\emptyset}$ must be replaced with

$$
\tilde{q}_{\emptyset}^{\prime} \equiv \frac{q(1-x)}{1-x[1-(1-q)(1-y)(1-\rho)]} .
$$

This expression differs from $\tilde{q}_{\emptyset}$, because monitoring never reveals side-effects when the firm's test fails. But, since $\partial \tilde{q}_{\emptyset} / \partial \rho>0$ (for $y<1$ ), the confidence effect of monitoring is still present. It can be shown that the relationship between the monitoring instruments can still be complementary and in this sense Proposition 3 is robust. Proposition 4 also goes through, although when the monitoring technology is powerful, the incentives to invest do not depend on the detection probability. Moreover, $\partial \tilde{q}_{\emptyset} / \partial y>0$ so that the scepticism effect of selective reporting is still present. Bounded average quality (Assumption 211) is still necessary and sufficient for investment in information when monitoring

\footnotetext{
${ }^{34}$ The policy $F_{S C E}=300$ and $\rho_{S C E}=0.63$, which implements mandatory disclosure with strong confidence effect in the first market, induces again a non-informative equilibrium in both markets. Overall welfare is only 1208. This policy performs relatively well, because the probability of detection is high and reveals the existence of side-effects frequently. The more realistic assumption of a convex cost function for monitoring, rather than our linear formulation, would make this policy less attractive.
} 
is successful. Therefore, the main forces of our model do not disappear when the agency focusses more on the discovery of selective reporting than on the state of the world.

A different question is monitoring that provides information on both states of the world. This weakens the confidence effect. But note that the optimal enforcement policy in Section 4 induces an intermediate rather than a strong confidence effect. In the extreme, when the agency is equally effective in discovering both states of the world, the confidence effect disappears entirely. But, since the firm has no incentive to hide 'good news', it is unclear that monitoring should invest scarce resources in this type of information, rather than in 'bad news'. Note also that even without the confidence effect, the scepticism effect of selective reporting is still present, as $\partial \tilde{q}_{\emptyset} / \partial y>0$. This increases the opportunity costs of information search and deters investment in information. Consider Example 1 . It is still possible that the introduction of monitoring eradicates selective reporting and induces the consumer to be trustful unless side-effects are discovered. The firm gains nothing from testing and only a non-informative equilibrium exists. Depending on the severity of side-effects this equilibrium might yield lower welfare than the informative selective reporting equilibrium before the introduction of monitoring. Therefore a similar logic to the one in the analysis of Section 4 might still apply.

\section{Conclusions}

The present paper contributed to deepen our understanding of the effects of enforcement of mandatory disclosure regulations. In our model a firm can invest in information about product quality and decide whether or not to disclose the findings. If the firm holds back information, it might be detected and fined. While we showed that such a monitoring policy can improve over laissez-faire, we also saw that optimal monitoring is determined by a trade-off between the quality and quantity of information provided. This trade-off involves important subtleties, including the fact that relationship between the detection probability and the fine might be complementary. We also showed that the welfare effects of mandatory disclosure depend on how it is enforced and that imperfect enforcement might be optimal. Lastly, the optimal fine might be smaller than the largest possible fine, even though the latter requires lower resource costs for inspections.

Our persuasion game with an endogenously informed sender might also shed some light on other situations. Consider the interaction between a firm, a rating agency and investors (see Faure-Grimaud et al., 2009). If the firm asks for a corporate governance rating and has the ownership of it, it might report the rating selectively. Mandatory disclosure, however, deters the firm's incentives to pay the agency for a rating. When there is no obligation to ask for a rating and ratings are valued by investors, our analysis implies that a similar trade-off between the quality and quantity of information to the one in the present paper appears. There might hence be situations in which it is optimal 
to enforce mandatory disclosure rules for ratings imperfectly.

The aim of the present paper was to provide a formal framework to think rigorously about enforcement. While our results uncover a trade-off that optimal enforcement must balance, we do not offer an empirical assessment of this trade-off. Future research should provide further guidelines when strict enforcement is desirable by quantifying the disincentive effect and the welfare consequences through empirical work for specific mandatory disclosure rules, like clinical trials.

There are, however, reasons to believe that the incentives of firms to search for information are an important concern. Indeed, drug approval often requires so-called postmarketing clinical trials and it is documented that firms fail to comply (US Food and Drug Administration, 2011; Fain et al, 2013). While this suggests that we can interpret our model as a benchmark situation in which post-marketing trials are either not required or not enforced, there is another enforcement problem when obliging firms to search for information. Thus an interesting avenue for future research considers two-dimensional policies that monitor both selective reporting and whether investment in information took place in the first place. It appears that the disincentive effect on information search is reduced, as a fine might be imposed when the firm is found out not to have searched. But we leave a rigorous analysis of the overall effects of monitoring and of the optimal two-dimensional monitoring policy for future research.

\section{References}

[1] Anderson, M. L.; K. Chiswell; E. D. Peterson; A. Tasneem; J. Topping; and R. M. Califf (2015), "Compliance with results reporting at ClinicalTrials.gov," New England Journal of Medicine 372, p. 1031-1039.

[2] Andreoni, J. (1991), "Reasonable Doubt and the Optimal Magnitude of Fines: Should the Penalty Fit the Crime?," Rand Journal of Economics 22 (3), p. 385395.

[3] Antman, E. M.; J. S. Bennett; A. Daugherty; C. Furberg; H. Roberts; K. A. Taubert (2007), "Use of nonsteroidal antiinflammatory drugs: an update for clinicians: a scientific statement from the American Heart Association," Circulation 115 (12), p. $1634-1642$.

[4] Armantier, O. and N. Treich (2009), "Star-shaped probability weighting functions and overbidding in first-price auctions," Economics Letters 104 (2), p. 83-85.

[5] Azoulay, P. (2002), "Do pharmaceutical sales respond to scientific evidence?" Journal of Economics and Management Strategy 11 (4), p. 551-594. 
[6] Becker, G.S. (1968), "Crime and punishment: an economic approach," Journal of Political Economy 76, p. 169-217.

[7] Bebchuk, L. A. and L. Kaplow (1992), "Optimal sanctions when individuals are imperfectly informed about the probability of apprehension," Journal of Legal Studies 21, p. 365-370.

[8] Berenson, A. (2006) "A 2nd Loss For Merck Over Vioxx," New York Times, April 6.

[9] Bullen, P.S. (1998), "A Dictionary of Inequalities," Pitman Monographs and Surveys in Pure and Applied Mathematics n. 97, CRC Press LLC.

[10] Chan, A.W.; F. Song; A. Vickers; et al. (2014), "Increasing value and reducing waste: addressing inaccessible research," Lancet 383, p. 257-266.

[11] Chateauneuf, A.; M. Cohen; I. Meilijson (2004), "Four notions of mean preserving increase in risk, risk attitudes and applications to the rank-dependent expected utility model," Journal of Mathematical Economics 40, p. 547-571.

[12] Corts, K.S. (2014), "Finite Optimal Penalties for False Advertising," Journal of Industrial Economics 62(4), p. 661-681.

[13] Couzin, J. (2004), "Drug research: legislators propose a registry to track clinical trials from start to finish," Science 305, p. 1695.

[14] Dahm, M.; P. González; and N. Porteiro (2009), "Trials, Tricks and Transparency: How Disclosure Rules Affect Clinical Knowledge," Journal of Health Economics 28, p. 1141-1153.

[15] Dahm, M.; P. González; and N. Porteiro (2016), "The Enforcement of Mandatory Disclosure Rules," CeDEx Discussion Paper 2016-19, University of Nottingham.

[16] De Angelis, C.; J.M. Drazen; F. A. Frizelle et al. (2004), "Clinical Trial Registration: A Statement from the International Committee of Medical Journal Editors," Annals of Internal Medicine, 141, p. 477-8.

[17] Di Tillio, A.; M. Ottaviani; and P.N. Sorensen (2015), "Persuasion Bias in Science: Can Economics Help?," working paper.

[18] Dranove, D. and G.Z. Jin (2010), "Quality Disclosure and Certification: Theory and Practice," Journal of Economic Literature 48 (4), p. 935-963.

[19] Drazen, J.M.; S. Morrissey; G.D. Curfman et al. (2007), "Editorial: Open Clinical Trials," The New England Journal of Medicine, 357 (17), p. 1756-7. 
[20] Dye, R.A. (1985), "Disclosure of Nonproprietary Information," Journal of Accounting Research 23, p. 123-145.

[21] Dye, R.A. (2017), "Optimal disclosure decisions when there are penalties for nondisclosure," RAND Journal of Economics 48 (3), p. 704-732.

[22] Fain, K.; M. Daubresse; and G. Alexander (2013), "The Food and Drug Administration Amendments Act and Postmarketing Commitments" Journal of the American Medical Association 310 (2), p. 202-204.

[23] Farell, J. (1986), "Voluntary Disclosure: Robustness of the Unraveling Result, and Comments on Its Importance," in Ronald E. Grieson, ed., Antitrust and Regulation, Lexington, MA: Lexington Books, p. 91-103.

[24] Faure-Grimaud, A.; E. Peyrache; and L. Quesada (2009), "The ownership of ratings," Rand Journal of Economics 40 (2), p. 234-257.

[25] Feess, E. and A. Wohlschlegel (2009), "Why higher punishment may reduce deterrence," Economics Letters 104, p. 69-71.

[26] Fung, A.; M. Graham; D. Weil (2007), "Full Disclosure: The Perils and Promise of Transparency," New York, Cambridge University Press.

[27] Garoupa, N. (1997), "The theory of optimal law enforcement," Journal of Economic Surveys 11 (3), p. 267-295.

[28] Goldacre, B. (2013) "Health Care's Trick Coin," New York Times, February 1.

[29] Gopal, A. D.; N. R. Desai; T. Tse; and J. S. Ross (2015), "Reporting of Noninferiority Trials in ClinicalTrials.gov and Corresponding Publications," Journal of the American Medical Association 313 (11), p. 1163-1165.

[30] Grabowski, H. and J. Vernon (1994), "Returns to R\&D on new drug introductions in the 1980s," Journal of Health Economics 13, p. 383-406.

[31] Grabowski, H.; J. Vernon; and J.A. DiMasi (2002), "Returns on research and development for 1990s. New Drug Introductions," Pharmacoeconomics 20 (3), p. 11-29.

[32] Grossman, S.J. (1981), "The Informational Role of Warranties and Private Disclosure about Product Quality," Journal of Law and Economics 24 (3), p. 461-483.

[33] Harrington, J.E. (2014), "Penalties and the Deterrence of Unlawful Collusion," Economic Letters 124, p. 33-36. 
[34] Henry, E. (2009), "Strategic disclosure of research results: The cost of proving your honesty," Economic Journal 119, p. 1036-1064.

[35] Henry, E. and M. Ottaviani (2017), "Research and the Approval Process: The Organization of Persuasion," working paper.

[36] Hudson, K. L. and F. S. Collins (2015), "Sharing and reporting the results of clinical trials," Journal of the American Medical Association 313, p. 355-356.

[37] Jovanovic, B. (1982), "Truthful Disclosure of Information," Bell Journal of Economics 13(1), p. 36-44.

[38] Kaplow, L. (1990), "A note on the optimal use of nonmonetary sanctions," Journal of Public Economics 42, p. 245-247.

[39] Kartik, N.; F. X. Lee; and W. Suen (2015), "A Theorem on Bayesian Updating and Applications to Signaling Games," working paper.

[40] Kartik, N.; F. X. Lee; and W. Suen (2017), "Investment in Concealable Information by Biased Experts," RAND Journal of Economics 48 (1), p. 24-43.

[41] Krumholz, H. M.; J. S. Ross; A. H. Presler; and D. S. Egilman (2007), "What have we learnt from Vioxx? ," British Medical Journal 334, p.120-123.

[42] Landsberger, M. and I. Meilijson (1990), "Lotteries, insurance and star-shaped utility functions," Journal of Economic Theory 52, p. 1-17.

[43] Malik, A. (1990), "Avoidance, screening and optimum enforcement," RAND Journal of Economics 21 (3), p. 341-353.

[44] Matthews, S. and A. Postlewaite (1985), "Quality Testing and Disclosure," Rand Journal of Economics 16 (3), p. 328-340.

[45] Milgrom, P. (1981), "Good News and Bad News: Representation Theorems and Applications," Bell Journal of Economics 12, p. 380-391.

[46] Milgrom, P. (2008), "What the seller won't tell you: persuation and disclosure in markets," Journal of Economic Perspectives 12, p. 380-391.

[47] Milgrom, P. and J. Roberts (1986), "Relying on the Information of Interested Parties," Rand Journal of Economics 17 (1), p. 18-32.

[48] Mookherjee, D. and I. P. L. Png (1992), "Monitoring vis-a-vis investigation in enforcement of law," American Economic Review 82, p. 556-565. 
[49] Piccolo, S.; P. Tedeschi; and G. Ursino (2015), "How limiting deceptive practices harms consumers," RAND Journal of Economics 46 (3), p. 611-624.

[50] Polinsky, A. M. and S. Shavell (1979), "The optimal trade-off between the probability and magnitud of fines," American Economic Review 69, p. 880-891.

[51] Polinsky, A. M. and S. Shavell (1991), "A note on optimal fines when wealth varies among individuals," American Economic Review 81, p. 618-621.

[52] Polinsky, A. M. and S. Shavell (2000), "The economic theory of public enforcement of law," Journal of Economic Literature 38, p. 45-76.

[53] Polinsky, A. M. and S. Shavell (2012), "Mandatory Versus Voluntary Disclosure of Product Risks," Journal of Law, Economic \& Organization 28 (2), 360-379.

[54] Prayle, A. P.; M. N. Hurley; and A. R. Smyth (2012), "Compliance with mandatory reporting of clinical trial results on ClinicalTrials.gov: cross sectional study," The BMJ 344.

[55] Rhodes, A. and C. Wilson (2017), "False advertising," RAND Journal of Economics, forthcoming.

[56] Schweizer, U. (2017), "Incentives to Acquire Information under Mandatory versus Voluntary Disclosure ," The Journal of Law, Economics, $\&$ Organization, 33 (1), p. 173-192.

[57] Seidmann, D.J. and E. Winter (1997), "Strategic information transmission with verifiable messages," Econometrica 65 (1), p. 163-169.

[58] Shavell, S. (1994), "Acquisition and Disclosure of Information Prior to Sale," RAND Journal of Economics 25 (1), p. 20-36.

[59] Shin, H. S. (1994), "The burden of proof in a game of persuasion," Journal of Economic Theory 64, p. 253-264.

[60] US Food and Drug Administration (2011), "Guidance for Industry: Postmarketing Studies and Clinical Trials - Implementation of $\S 505(\mathrm{o})(3)$ of the Federal Food, Drug, and Cosmetic Act," April, available at http://www.fda.gov/downloads/ Drugs/GuidanceComplianceRegulatoryInformation/Guidances/UCM172001 .pdf, accessed on $08 / 06 / 2018$.

[61] Wood, A.J.J. (2009) "Progress and Deficiencies in the Registration of Clinical Trials," Special Report, New England Journal of Medicine 360, p. 824-830. 


\section{A Appendix: Proofs}

\section{A.1 Proof of Proposition 3}

Consider $\tilde{F}$ as defined in $(8)$. Both instruments are substitutes provided $\frac{\partial \tilde{F}_{y}(q, \rho)}{\partial \rho}<0$, for every $\rho \in(0,1)$. Computing the derivative we obtain:

$$
\frac{\partial \tilde{F}_{y}(q, \rho)}{\partial \rho}=\frac{1}{\rho}\left[\left.(1-\rho) \frac{d \pi}{d q}\right|_{\tilde{q}_{\emptyset}} \frac{\partial \tilde{q}_{\emptyset}}{\partial \rho}-\frac{\pi\left(\tilde{q}_{\emptyset}\right)}{\rho}\right] .
$$

Using $\frac{\partial \tilde{q}_{\emptyset}}{\partial \rho}=\tilde{q}_{\emptyset} \frac{(1-q)(1-x y)}{1-x q-(1-q)[\rho+x y(1-\rho)]}$, we obtain $\frac{\partial \tilde{F}_{y}(q, \rho)}{\partial \rho}<0$ if and only if 14 holds. Q.E.D.

\section{A.2 Proof of Proposition 4}

The result follows from computing the derivatives of (12). Consider first an increase in the fine. For $F \leq \tilde{F}_{0}(q, \rho)$ and $F \geq \tilde{F}_{1}(q, \rho)$, we obtain

$$
\frac{\partial \mathbb{K}_{t}}{\partial F}=-(1-q) \rho<0 \quad \text { and } \quad \frac{\partial \mathbb{K}_{t}}{\partial F}=0
$$

respectively. Consider now an increase in the detection probability. For $F \leq \tilde{F}_{0}(q, \rho)$ and $F \geq \tilde{F}_{1}(q, \rho)$, we obtain

$$
\begin{aligned}
\frac{\partial \mathbb{K}_{t}}{\partial \rho} & =-\left.q \frac{d \pi}{d q}\right|_{\tilde{q}_{\emptyset}^{S R}} \frac{\partial \tilde{q}_{\emptyset}^{S R}}{\partial \rho}-(1-q) F<0 \quad \text { and } \\
\frac{\partial \mathbb{K}_{t}}{\partial \rho} & =-\left.[1-\rho(1-q)] \frac{d \pi}{d q}\right|_{\tilde{q}_{\emptyset}^{H R}} \frac{\partial \tilde{q}_{\emptyset}^{H R}}{\partial \rho}+(1-q) \pi\left(\tilde{q}_{\emptyset}^{H R}\right),
\end{aligned}
$$

respectively. The last expression is strictly negative if and only if

$$
\left.\frac{d \pi}{d q}\right|_{\tilde{q}_{\emptyset}^{H R}}>\frac{\pi\left(\tilde{q}_{\emptyset}^{H R}\right)(1-q)}{[1-\rho(1-q)] \frac{\partial \tilde{q}_{\emptyset}^{H R}}{\partial \rho}}
$$

Notice that the inequality in (2) is equivalent to

$$
\frac{d \pi(q)}{d q}>\frac{\pi(q)}{q}
$$

Since $\frac{\partial \tilde{q}_{\emptyset}^{H R}}{\partial \rho}=\tilde{q}_{\emptyset}^{H R} \frac{1-q}{1-\rho(1-q)}$, we obtain that $\frac{\partial \mathbb{K}_{t}}{\partial \rho}<0$ if and only if 20 holds. Q.E.D. 